\title{
Spontaneous Intracerebral Hemorrhage in Pediatric Patients with Hemophilia A: Case Report and Review of Perioperative Management of Clotting Factor Concentrates
}

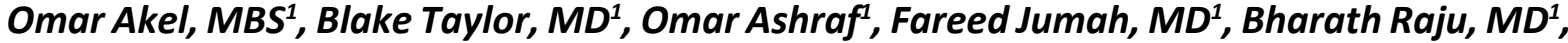 \\ Priyank Khandelwal, $M D^{2}$, Margaret Pain, $M D^{1}$, Stephen Johnson, $M D^{1}$, Anil Nanda, $M D^{1}$, \\ Sudipta Roychowdhury, $M D^{1}$ and Gaurav Gupta, $M D^{1^{*}}$
}

${ }^{1}$ Department of Neurosurgery, Rutgers - Robert Wood Johnson Medical School \& University Hospital, New Jersey, USA

${ }^{2}$ Department of Neurological Surgery and Neurology, Rutgers New Jersey Medical School, New Jersey, USA

*Corresponding author: Gaurav Gupta, MD, FAANS, FACS, Associate Professor, Department of Neurosurgery, Rutgers Robert Wood Johnson Medical School, 10 Plum Street, 5th Floor, New Brunswick, New Jersey, 08903-2601, USA, Tel: 732$235-6333$

\begin{abstract}
Introduction: Intracerebral hemorrhage $(\mathrm{ICH})$ is the leading cause of death in patients with hemophilia. The incidence of $\mathrm{ICH}$ is up to 50 times greater than that of the general population, and most frequently occurs in children less than two years of age and among those with the severe forms of the disease. The ideal perioperative management of this patient population, however, remains unclear.

Case report: A 9-month-old boy with a known history of hemophilia $A(H A)$ presented to the emergency department with lethargy, anorexia, and fever. The family denied any history of trauma or prior bleeding episodes. Further evaluation revealed a right-sided acute intraparenchymal hemorrhage causing significant midline shift and herniation. Five hundred units of factor VIII were promptly administered, and a right sided decompressive hemicraniectomy was performed. Maintaining adequate factor VIII activity levels with a continuous infusion was ineffective in the perioperative period, and he was subsequently placed on a regimented bolus schedule, with additional factor VIII administered prior to invasive procedures. The patient ultimately made an excellent recovery without any further complications.

Conclusion: Intracranial hemorrhage should be suspected in infants and young children who have a known history of hemophilia and present with altered mental status. Prompt administration of clotting factor concentrate is imperative prior to neurological surgery and in the post-operative
\end{abstract}

period, so as to minimize risk of hemorrhage expansion and neurological deterioration. Failure to maintain adequate factor VIII activity levels with a continuous infusion may be managed with a regimented bolus schedule supplemented with additional boluses prior to invasive procedures.

\section{Keywords}

Hemophilia, Intracranial hemorrhage, Factor VIII, Perioperative management, Regimented bolus, Continuous infusion

\section{Introduction}

Hemophilia A (HA) is an X-linked recessive bleeding disorder that accounts for $80 \%$ of all hemophilia cases. $\mathrm{ICH}$ is the leading cause of death in patients with hemophilia and accounts for $20 \%$ of non-infectious deaths, as reported in countries with developed healthcare systems [1]. Neurosurgical intervention in the acute setting of intracranial hemorrhage in patients with $\mathrm{HA}$ is often reserved for those with a deteriorating neurological exam and/or clinically significant hemorrhage with mass effect. Beyond prompt surgical intervention, the perioperative management of $\mathrm{HA}$ is of paramount importance to optimize outcomes. Guidelines for perioperative management have attempted to address this yet practical challenges remain [2]. Here we discuss the case of a child with HA who required an urgent craniectomy for anon-

Citation: Akel O, Taylor B, Ashraf O, Jumah F, Raju B, et al. (2021) Spontaneous Intracerebral Hemorrhage in Pediatric Patients with Hemophilia A: Case Report and Review of Perioperative Management of Clotting Factor Concentrates. Neurosurg Cases Rev 4:081. doi.org/10.23937/26434474/1710081

Accepted: September 24, 2021; Published: September 26, 2021

Copyright: (c) 2021 Akel O, et al. This is an open-access article distributed under the terms of the Creative Commons Attribution License, which permits unrestricted use, distribution, and reproduction in any medium, provided the original author and source are credited. 


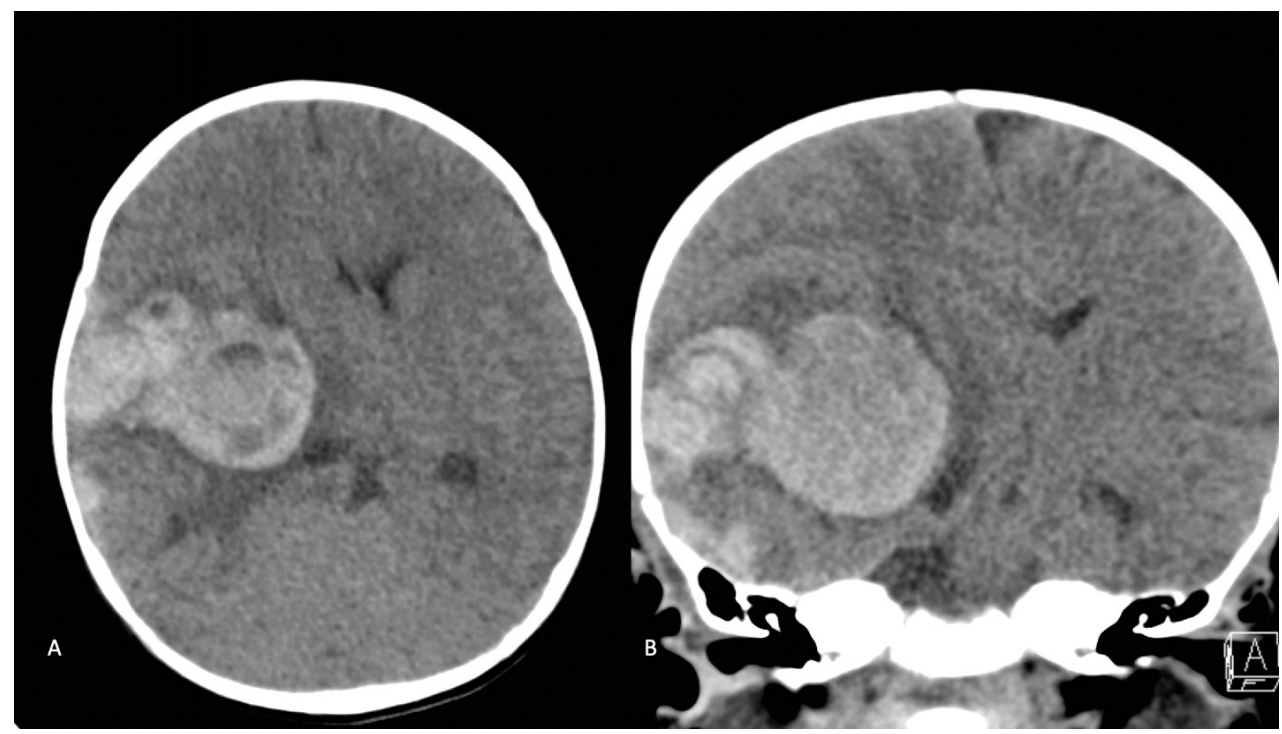

Figure 1: A) Non-Contrast Axial; B) Coronal. CT the head demonstrating a $5.6 \times 3.7 \mathrm{~cm}$ acute intraparenchymal hematoma centered in the right basal ganglia with an associated $12 \mathrm{~mm}$ leftward midline shift and right sided uncal herniation with an asymmetrically enlarged temporal horn of the right lateral ventricle. There are also multifocal right frontal-temporal-parietal acute extra-axial hemorrhages as well as a right posterior falcine/tentorial subdural hematoma.

traumatic $\mathrm{ICH}$, and review the literature describing the challenges, nuances, and specific regimens of clotting factor replacements in neurosurgical patients with $\mathrm{HA}$, and their respective outcomes.

\section{Case Report/Case Presentation}

A 9-month-old full-term African American male delivered via uncomplicated vaginal delivery with a known history of HA presented to the emergency department for fatigue and decreased oral intake. One week prior to admission, he had intermittent fevers with a maximum temperature of $39.4{ }^{\circ} \mathrm{C}\left(102.9^{\circ} \mathrm{F}\right)$, and then developed fatigue and decreased feeding two days prior to presentation. On the day of admission, he began to experience right sided periorbital tenderness, worsened lethargy, and anorexia. The parents denied any recent trauma, although reported occasional bruising on the patient's lower extremities when crawling. The patient had no prior history of spontaneous bleeding secondary to $\mathrm{HA}$ and had never received a clotting factor treatment. He was not taking any medication.

On initial exam, the child was lethargic, protecting his airway, opening his eyes to stimulation, and moving all four extremities symmetrically. Pupils were equal and reactive to light bilaterally. He was found to be febrile to $38.2^{\circ} \mathrm{C}\left(100.8{ }^{\circ} \mathrm{F}\right)$, and vital signs showed a heart rate (HR) of 115, blood pressure (BP) of 107/56, saturating at $100 \%$ on room air, and he weighed $9.4 \mathrm{Kg}$ $\left(62.5^{\text {th }}\right.$ percentile). Laboratory studies revealed anemia (Hemoglobin of $6.3 \mathrm{~g} / \mathrm{dl}$ ). In the emergency department, the patient received 1 unit of packed red blood cells ( $p R B C)$, fluid resuscitation, acetaminophen for the fever, and broad-spectrum antibiotics for possible meningitis.

Given the history of $\mathrm{HA}$, a computed tomography (CT) scan of the head was ordered, which demonstrated a $5.6 \times 3.7 \mathrm{~cm}$ acute intraparenchymal hematoma (IPH) centered on the right basal ganglia with associated $12 \mathrm{~mm}$ of leftward midline shift and right uncal herniation (Figure 1). At this time, the patient was given $500 \mathrm{IU}$ factor VIII (Advate), 10g mannitol (1 g/kg), and $200 \mathrm{mg}$ levetiracetam (20 mg/kg). CT angiogram was negative for an underlying vascular malformation or aneurysm (Figure 2). Given the significant midline shift as well as uncal and subfalcine herniation, the patient was taken to the operating room emergently for a right-sided decompressive hemicraniectomy and evacuation of the hematoma.

\section{Operative Course}

Intra-operatively, after removing the hemicraniectomy bone flap, diffuse bleeding from the skin, subcutaneous tissues, and bone was noted, at which point 500 IU of factor VIII were administered, with improvement in hemostasis. After opening the dura, a large subdural hematoma was evacuated, which was not seen on initial CT. Only evacuation of the liquid portion of the $\mathrm{ICH}$ was performed as most it was a hardened, densely organized hematoma. In addition, several sylvian fissure vessels were encountered within this hard organized hematoma, limiting the amount that could be evacuated. The portion of the hematoma that was densely adherent to the brain parenchyma was also left behind. Additional hemostasis was achieved with meticulous use of bipolar electrocautery, Gelfoam (Pfizer, New York, NY), thrombin, Surgicel (Johnson and Johnson, New Brunswick, NJ), and Surgiflo (Ethicon, Somerville, NJ). Estimated intraoperative blood loss was $200 \mathrm{ml}$, for which he received a total of $300 \mathrm{ml}$ of normal saline, $300 \mathrm{ml}$ of platelets, $130 \mathrm{ml}$ of fresh frozen plasma, and $360 \mathrm{ml}$ of pRBC. Postoperative hemoglobin was $10.1 \mathrm{~g} / \mathrm{dl}$.

\section{Post-Operative Course}

Postoperatively, the patient was taken to the 


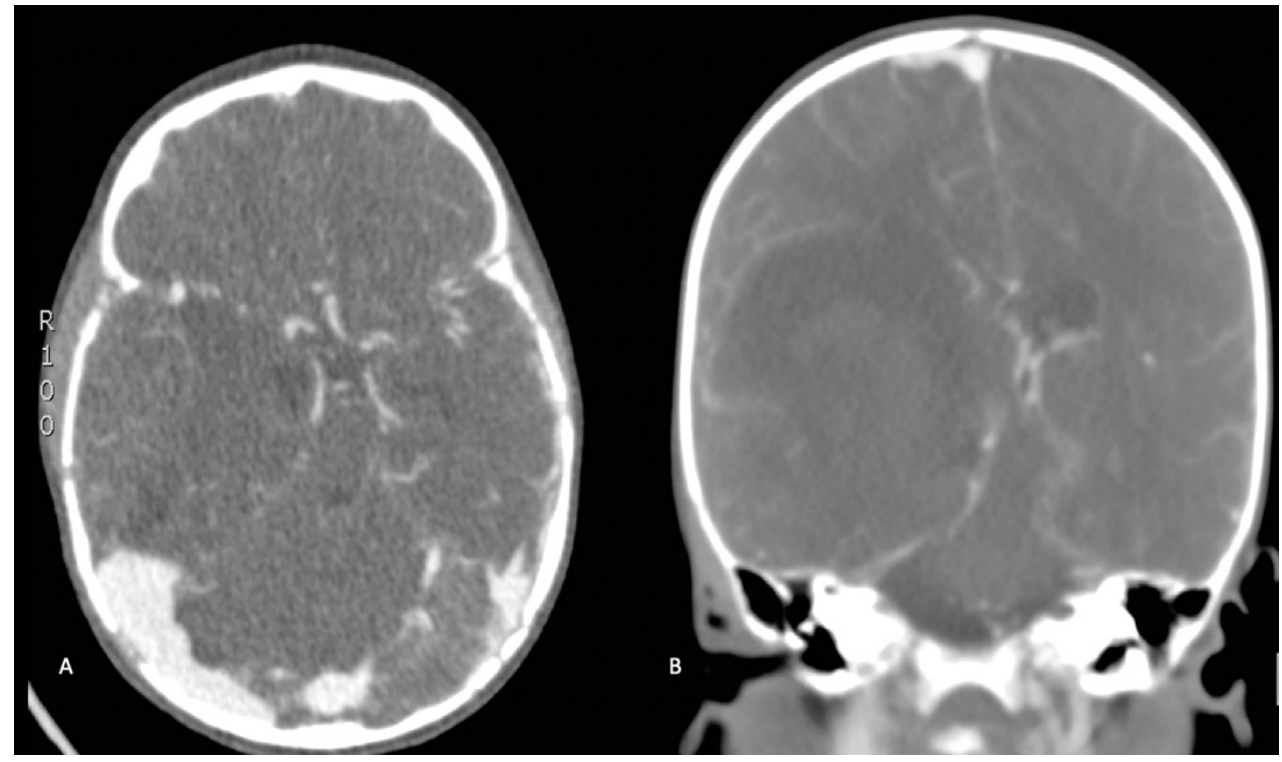

Figure 2: A) Axial; B) Coronal. CT Angiography: Demonstrating a right basal ganglia centric intraparenchymal hemorrhage causing mass effect with a $12 \mathrm{~mm}$ midline shift, right uncal herniation. There is no definite arterial blush suggestive of active bleeding within the hematoma. No suggestion of underlying vascular malformation.

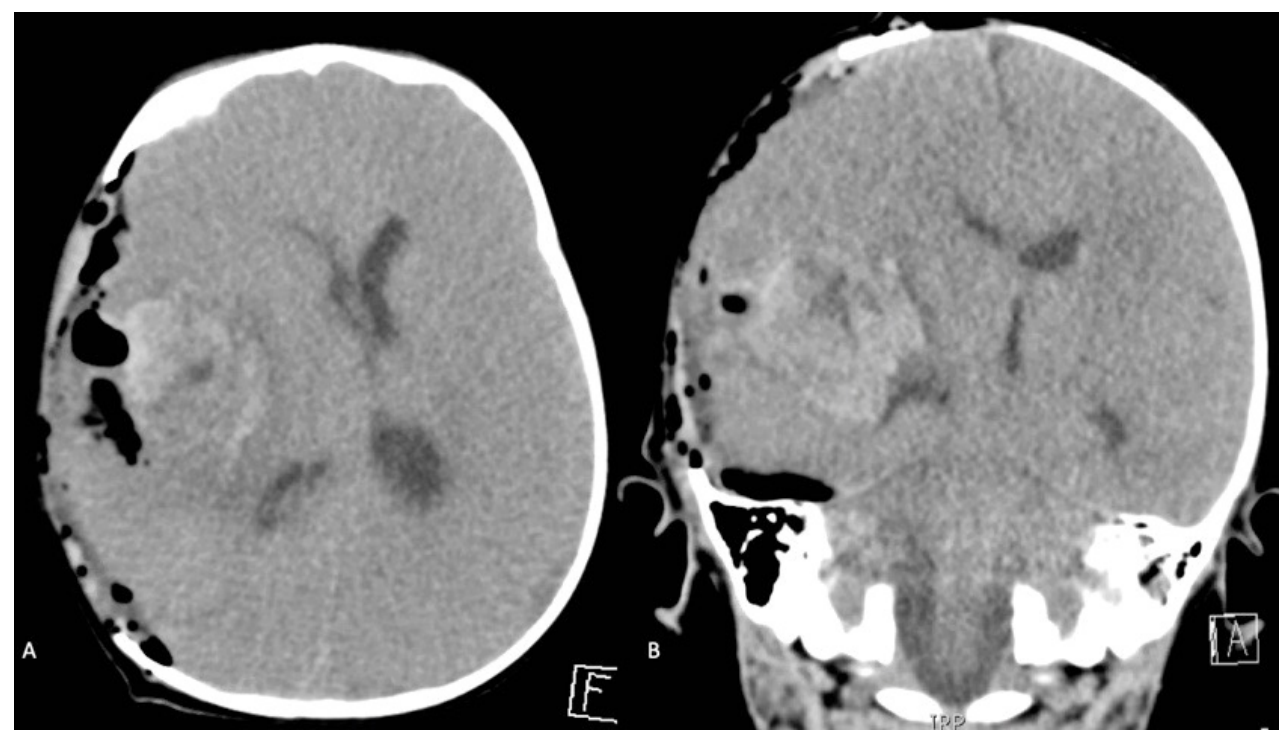

Figure 3: A) Post-operative Non-contrast Axial; B) Coronal. CT redemonstrating a large right basal ganglia intraparenchymal hemorrhage with improved midline shift to $8 \mathrm{~mm}$ from $12 \mathrm{~mm}$.

pediatric intensive care unit, where he remained intubated, and was started on $3 \mathrm{u} / \mathrm{kg} / \mathrm{hr}$ of factor VIII. On exam he was noted to be bradycardic, had no eye opening, and had left-sided hemiplegia. Pupils were $2 \mathrm{~mm}$ and reactive bilaterally, and the craniectomy site was soft and non-bulging. Postoperative CT head showed improved midline shift (12 to $8 \mathrm{~mm}$, see Figure $3)$, although there was developing ventriculomegaly and loss of gray-white differentiation, suggestive of diffuse cerebral edema. Medical treatment was optimized with mannitol boluses and a $3 \% \mathrm{NaCl}$ drip, maintaining sodium in the $150-155 \mathrm{mEq} / \mathrm{L}$ range.

A postoperative coagulation profile demonstrated a low Factor VIII coagulation activity of $30 \%$, for which he was given another bolus of $500 \mathrm{IU}$ of Factor VIII, and his infusion rate was increased to $4 \mathrm{u} / \mathrm{kg} / \mathrm{hr}$. Although
Factor VIII activity improved to $112 \%$ on repeat studies three hours later, it again decreased to $38 \%$ at 12 hours, for which he was given another bolus and the infusion rate was increased to $5 \mathrm{u} / \mathrm{kg} / \mathrm{hr}$. Follow up activity eight hours later was $115 \%$.

To rule out an occult vascular lesion, he was then taken for a formal cerebral angiogram on postoperative day (POD) 1, which was negative (Figure 4). Repeat Factor VIII activity approximately four hours later was 79\%. At this point his Factor VIII levels continued to downtrend, with the lowest activity level on POD 2 being $15 \%$. The decision was made to discontinue the infusion and begin a bolus regimen of $50 \mathrm{u} / \mathrm{kg}$ every six hours. Over the next two days, his Factor VIII levels continued to fluctuate with a predominantly upward 


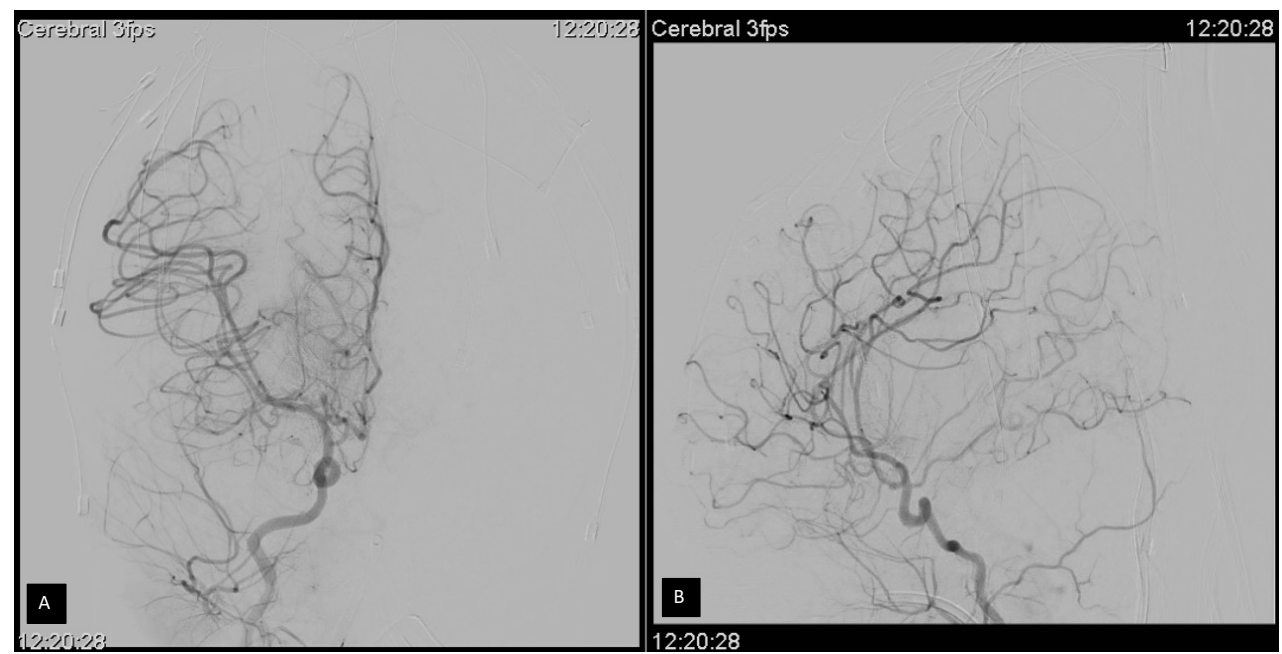

Figure 4: A) Post-operative Coronal; B) Sagittal. Right sided Cerebral Angiogram demonstrating normal cerebrovascular anatomy with no definitive underlying aneurysms, vascular malformations, dissections, or stenosis.
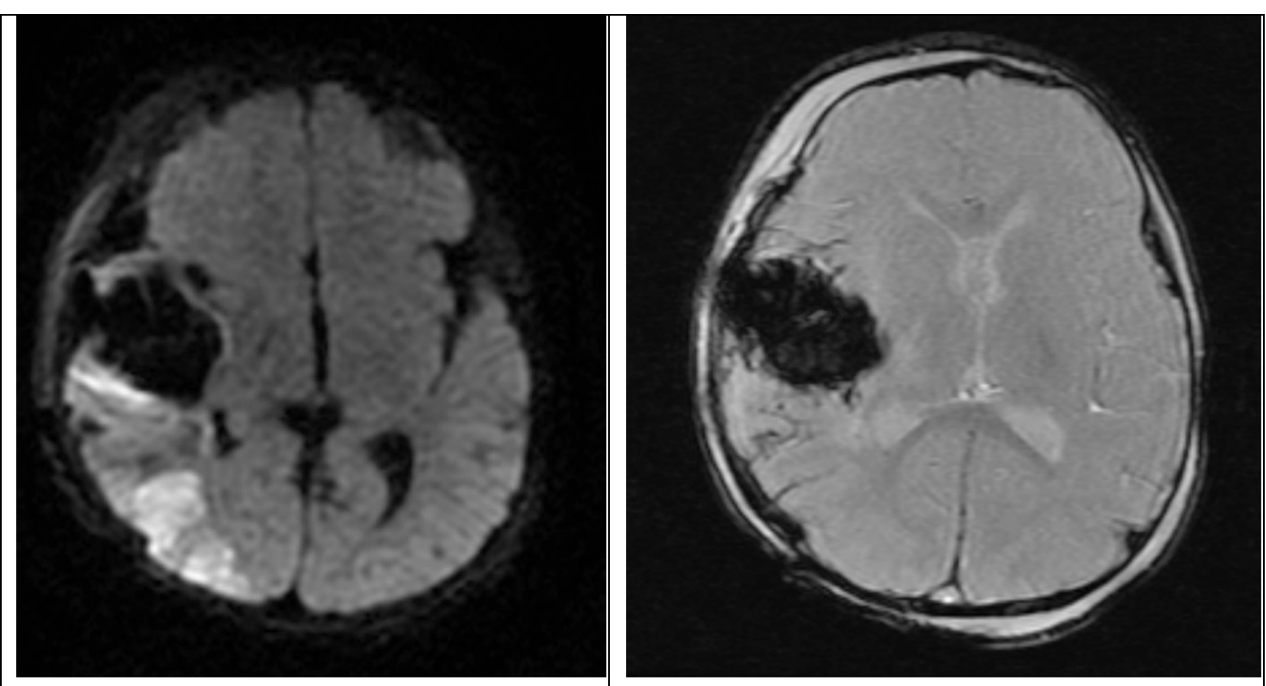

A

B
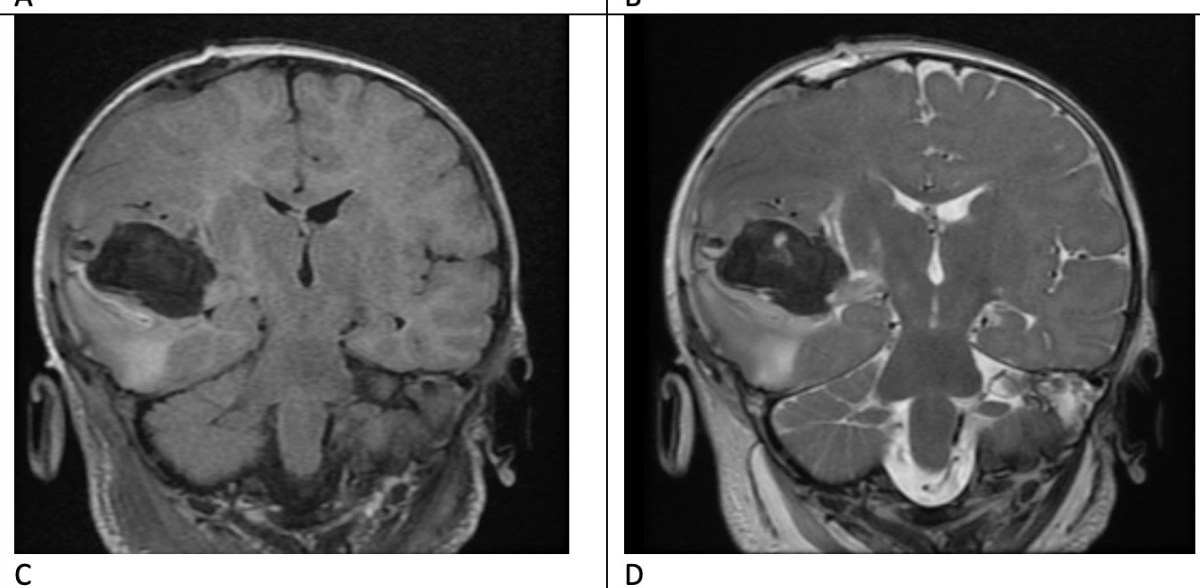

Figure 5: Post-operative Magnetic Resonance Imaging (MRI) demonstrating ischemia of the right middle cerebral artery territory and residual hematoma with improved mid-line shift on various sequences. A) Axial Diffusion Weighted Image, B) Axial Gradient Recalled Echo (GRE), C) Coronal T2 Flair sequence, D) Coronal T2 Fast Spin Echo (FSE).

trend, reaching a maximum of $254 \%$ after a 500 IU bolus on POD 5. Over the following week, his Factor VIII dosing continued to be titrated; ultimately, he was continued on $250 \mathrm{IU}$ every six hours.

Although an MRI on POD 2 demonstrated ischemia of the right middle cerebral artery (MCA) territory (Figure 5), gray-white matter differentiation was largely preserved. He demonstrated neurological improvement over the following two weeks; on POD 9, the patient was successfully extubated, and he was awake and alert, opening eyes spontaneously, tracking, and moving all 


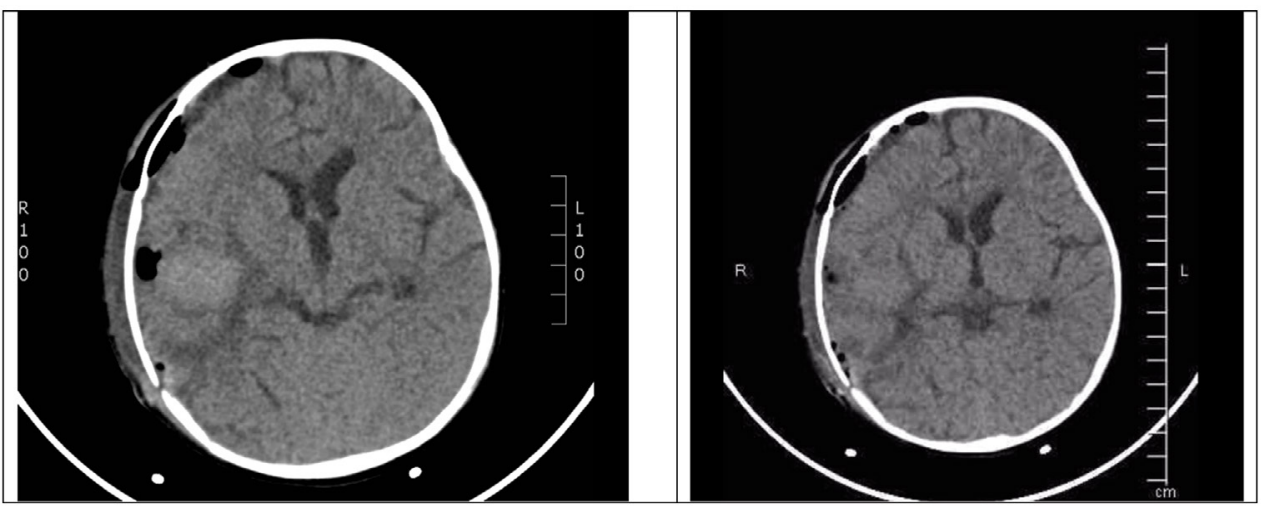

Figure 6: Post-cranioplasty non-contrast axial CT images demonstrating post-operative changes. Improved mid-line shift, and stable ventricular size.

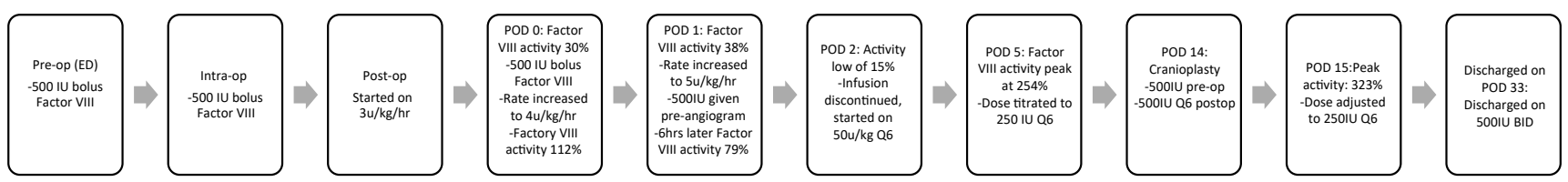

Figure 7: Summary of clotting factor concentrate administered in the perioperative period.

four extremities with greater activity on the right side than the left.

A cranioplasty was performed on POD 14 , as the flap was sufficiently soft. Preoperatively he was bolused 500 IU of Factor VIII and continued on 500 IU every six hours. The following day his Factor VIII activity level was found to be $323 \%$, and his dose was adjusted back to $250 \mathrm{IU}$ every six hours. There was no evidence of active bleeding or extravasation from the wound site, and the dressing was removed on POD 2. There were no further complications after the cranioplasty (Figure $6)$, or deterioration in neurological status. Figure 7 summarizes clotting factor concentrate administered in the perioperative period.

The patient was discharged to a specialized pediatric rehabilitation center for physical and occupational therapy on postoperative day 33 following the initial surgery. At the time of discharge, he was noted to be awake, alert, sitting up in bed, smiling, playful, and moving all four extremities symmetrically. Given his spontaneous hemorrhagic episode, a Permacath was placed during this hospitalization for lifelong factor VIII therapy. Ultimately the patient was discharged with a nasogastric tube, levetiracetam $40 \mathrm{mg} / \mathrm{kg} /$ day BID, and recombinant factor VIII 500 IU BID.

\section{Discussion/Conclusion}

$\mathrm{ICH}$ in a child with Hemophilia $A$ is a neurosurgical emergency that requires special considerations and a multidisciplinary approach. We describe our institutional experience with and nuances of treating an infant with severe HA who presented with spontaneous $\mathrm{ICH}$, discuss perioperative factor VIII management, review the literature, and propose a solution to patients with inadequate response to continuous infusions $(\mathrm{Cl})$ of factor VIII.

The incidence of $\mathrm{ICH}$ is 20 to 50 times greater among patients with hemophilia than those without the condition [3], and most frequently occurs in children with severe forms of the disease in the first two years of life, particularly if they are not receiving clotting factor prophylaxis $[1,4]$. This presents unique challenges in the emergent neurosurgical setting. Given that the prevalence of severe Hemophilia $A$ is reported to be 6 per 100,000 in males and $\mathrm{ICH}$ affects $3-10 \%$ of them, resulting in a mortality rate of up to $20 \%$, evaluation of nuances in neurosurgical perioperative management is paramount to improving outcomes $[3,5,6]$.

Current world federation of hemophilia (WFH) guidelines recommend that if there is any external evidence of head trauma or clinical suspicion of intracranial hemorrhage in this population, immediate treatment with clotting factor concentrate (CFC) should be administered prior to, and without waiting for, results of further radiographic or laboratory tests [2]. The appropriate dosing in the acute setting of intracranial hemorrhage is subject to the target factor VIII activity level which has been conventionally defined as 80$100 \mathrm{IU} / \mathrm{dL}$ (80-100\%) for ICH [2,3,7-11]. Achieving the appropriate plasma activity level can be accomplished by administering $1 \mathrm{IU} / \mathrm{kg}$ of either recombinant or plasma derived factor VIII for every $2 \mathrm{lU} / \mathrm{dL}(2 \%)$ increase in activity level desired $[9,12]$. This calculation assumes the absences of inhibitors, which may develop with chronic treatment, and is dependent on individual factors such as body mass index (BMI) [13]. Therefore, a dose of 50 
$\mathrm{IU} / \mathrm{kg}$ in the setting of intracranial hemorrhage would be expected to achieve a factor VIII activity level of $100 \%$ [14].

Previous reports that document neurosurgical interventions in HA patients are variable in their approach to correcting the coagulopathy. Historically, attempts to correct the clotting factor deficiencies in the setting of $\mathrm{ICH}$ with fresh blood and/or fresh plasma resulted in the death of upwards of two thirds of patients [15]. To avoid hypervolemia and brain edema, Carrea, et al. developed FIOta (tannic acid precipitate of Blombäck's FI-O fraction), a factor VIII preparation ten times more concentrated than human plasma [15]. Cryoprecipitate later emerged as the mainstay of treatment, demonstrating efficacy in elevating Factor VIII activity levels perioperatively for neurosurgical intervention in $\mathrm{ICH}$ with safe evacuation of hematomas $[16,17]$. Cryoprecipitate, however, had varying levels of Factor VIII depending on its preparation [16].

With the introduction of CFCs, much of the guidance is aimed at reaching and maintaining an appropriate factor VIII concentration level but there is no clear consensus on the optimal methodology to achieve this in the emergent perioperative setting. In our literature review, there were eight reports (and a total of 17 patients) that detailed perioperative regimens among non-traumatic pediatric $\mathrm{HA}$ patients with $\mathrm{ICH}$ (Table 1) [7,10,11,18-22]. Overall, management has largely been a combination of continuous infusions, boluses, and/or a defined infusion interval. Four of the eight reports (50\%) clearly reported a bolus of Factor VIII on presentation $[10,18-20]$. Following the initial intervention, three (37.5\%) studies transitioned to a continuous infusion of factor VIII and corticosteroids $[10,19,20]$. Two reported their hourly infusion rate $[10,20]$, the third reported a daily rate [19]. Five studies (62.5\%) utilized a scheduled regimen consisting of either a bolus or infusion at defined intervals [7,11,18,21,22]. One case was transitioned from a continuous infusion on postoperative day 7 to a bolus schedule for four weeks [20]. Titration strategies of Factor VIII and duration of treatment varied significantly between studies, however all patients included in the analysis survived to discharge. One patient developed inhibitors to Factor VIII after 10 days of treatment and was transitioned to activated factor VII (rFVIIa; NovoSeven) [10].

During the care of our patient, a bolus of $50 \mathrm{IU} / \mathrm{kg}$ of Factor VIII was given empirically in the emergency room pre-operatively. Intra-operatively, since the patient continued to have diffuse extravasation, another $50 \mathrm{IU} /$ $\mathrm{kg}$ bolus was given. Post-operatively, titrating up to 5 $\mathrm{u} / \mathrm{kg} / \mathrm{hr}$ of factor VIII remained inadequate and often required intermittent boluses of factor VIII to maintain a target activity level of $>80 \%$. In coordination with the pediatric hematology team, we opted to discontinue continuous infusions and begin a scheduled bolus regimen and titrated accordingly to the target Factor VIII activity level.

Continuous infusions have several advantages over boluses, including avoidance of often unpredictable peaks and troughs, and more economical use of Factor VIII, as higher plasma activity levels may often be achieved with less factor product [23]. However, clinically sufficient factor VIII activity may be related to variations in its clearance from the plasma, which prior authors have suggested may increase immediately after surgery and with extensive blood loss [2,12]. These perioperative fluctuations in the rate of Factor VIII degradation pose a challenge to appropriately titrating continuous infusions, at a time when effective hemostasis is needed most. In our patient, the continuous infusions did not maintain reliable and adequate factor activity levels in the perioperative period, and as a result we opted for a regimented bolus schedule titrated to our target levels with supplemental infusions prior to invasive procedures. Specifically, with a target activity level of $100 \%$, we bolused recombinant factor VIII at a dose of $50 \mathrm{IU} / \mathrm{kg}$ prior to the cerebral angiogram and cranioplasty, which proceeded without significant hemorrhagic complications. In effect, utilizing a bolus regimen, and periodically checking factor VIII levels, may be ideal perioperatively for HA patients who require immediate neurosurgical evacuation of an intracranial hematoma.

Two major factors that should be considered in addition to the administration regimen are the half-life of Factor VIII and the potential for formation of antifactor VIII antibodies. The half-life of standard half-life (SHL) recombinant Factor VIII such as Advate (Takeda; Tokyo, Japan) used at our institution is approximately 8-12 hours. The extended half-life (EHL) products alternatively have half-lives of approximately 12-19 hours; however, the half-life may vary with age and typically the half-life extension is minimal in children [2]. The formations of antibodies against factor VIII have been shown to be a challenge when treating HA patients with factor VIII. The incidence of inhibitor development is up to $41 \%$ in those treated within the first month of life, but the risk decreases to $18 \%$ in those treated after 18 months [24]. Additionally, the risk of inhibitor development is significantly higher in patients with severe HA (12-13\% compared to $5-7 \%$ seen in hemophiliacs overall) [25]. Risk factors for forming anti-Factor VIII antibodies include patients who are previously untreated, intense early treatment, higher dosage, and treatment for surgical procedures [24]. Hemophilia A patients who develop inhibitors generally do so within the first 40 days after exposure to Factor VIII, with a median onset of 14 days in the pediatric population [24,25]. In the case we presented, there was no concern that our patient's lack of response to continuous infusions was due to an inhibitor. This is due to the fact that this was his first treatment with 

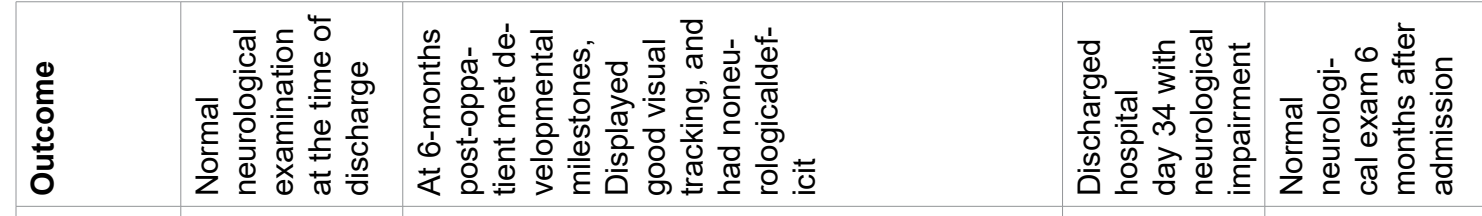

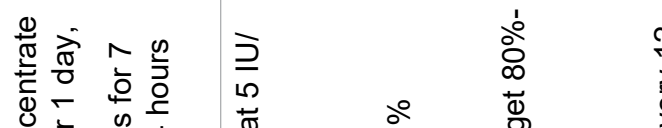

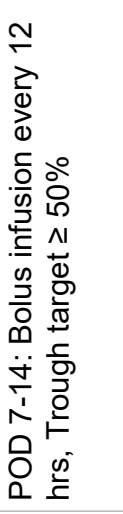

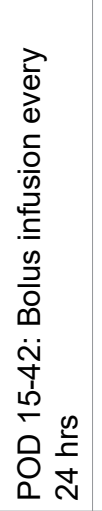

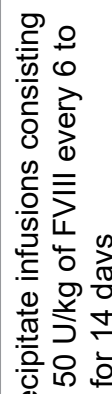

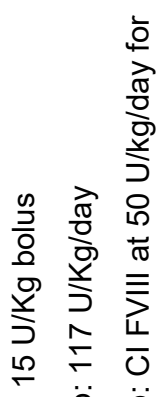

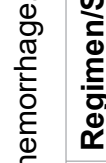

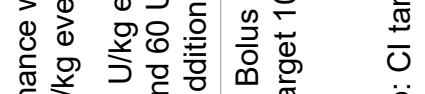

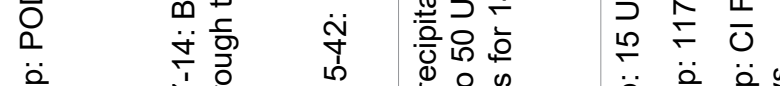

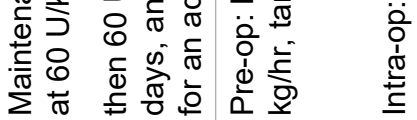

잉

일

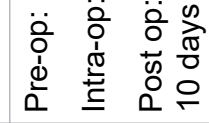

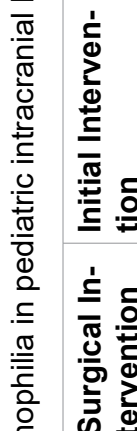

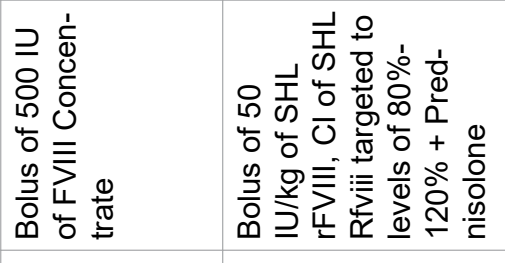

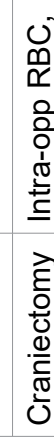

$8+\frac{0}{0}$

兽足

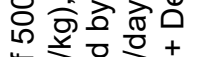

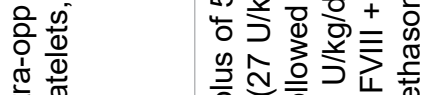

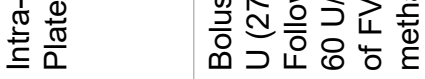

$\div$

这这妾

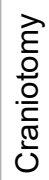

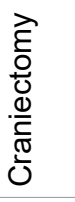

寗

(

象

厓

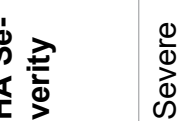

Q

폼

₹

政

1
0
0
0
0
0
$\vdots$
0

(a)

के

离

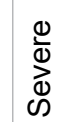

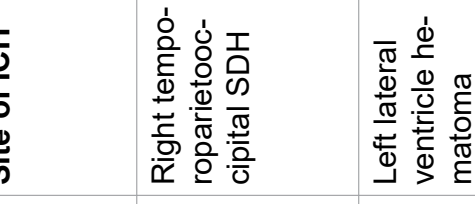

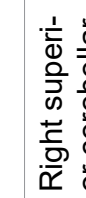

这

告

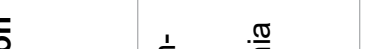

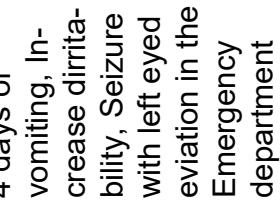

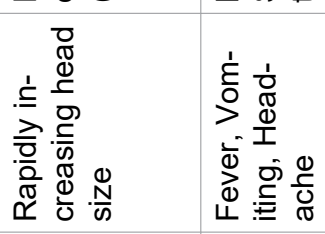

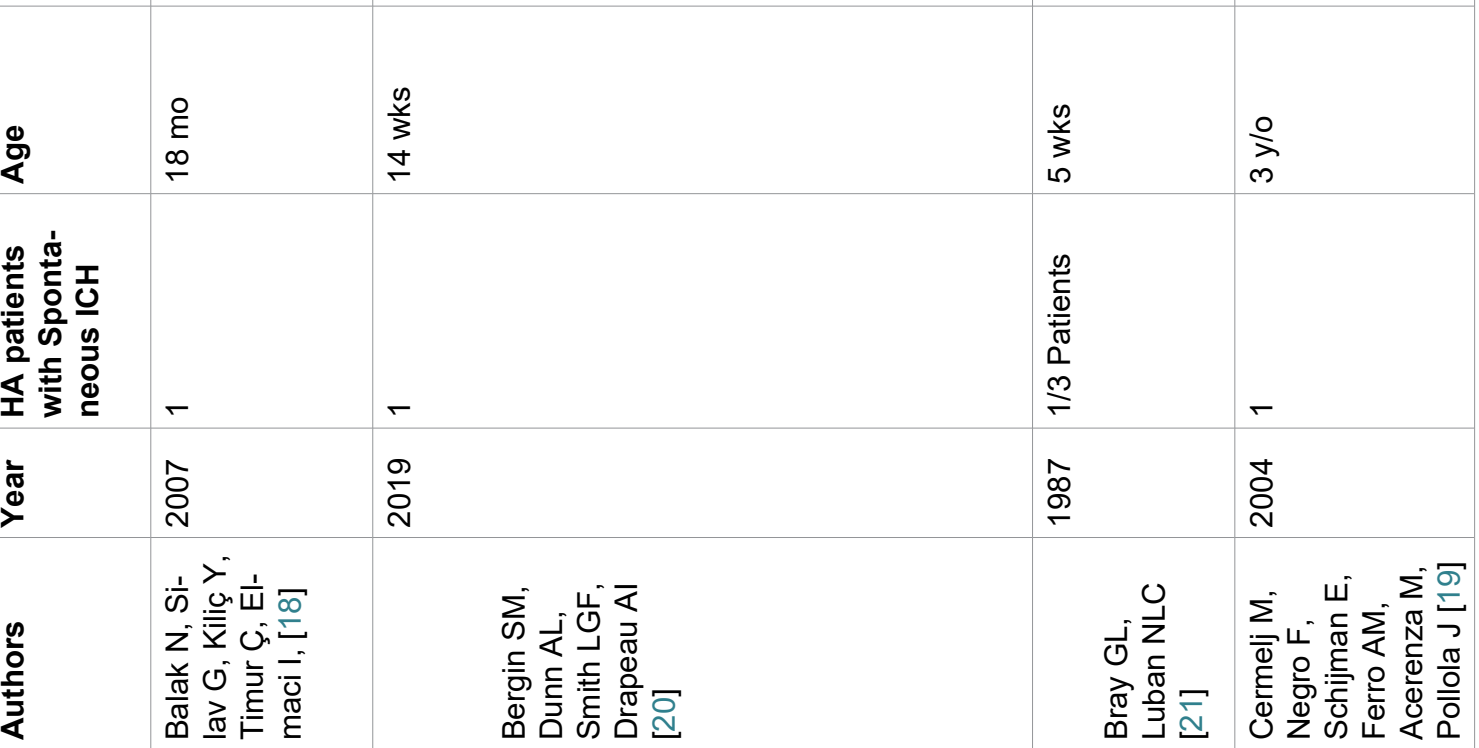




\begin{tabular}{|c|c|c|}
\hline 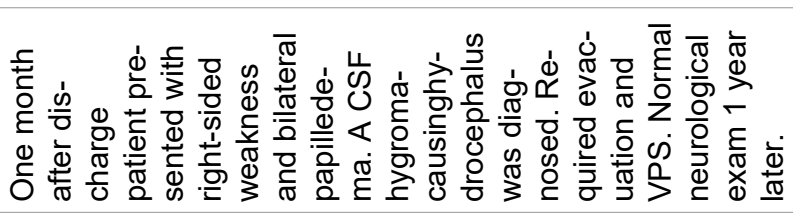 & 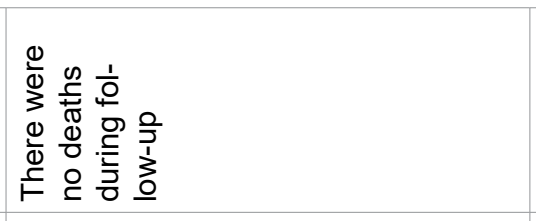 & 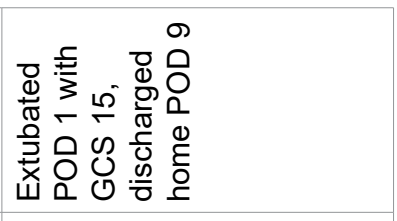 \\
\hline 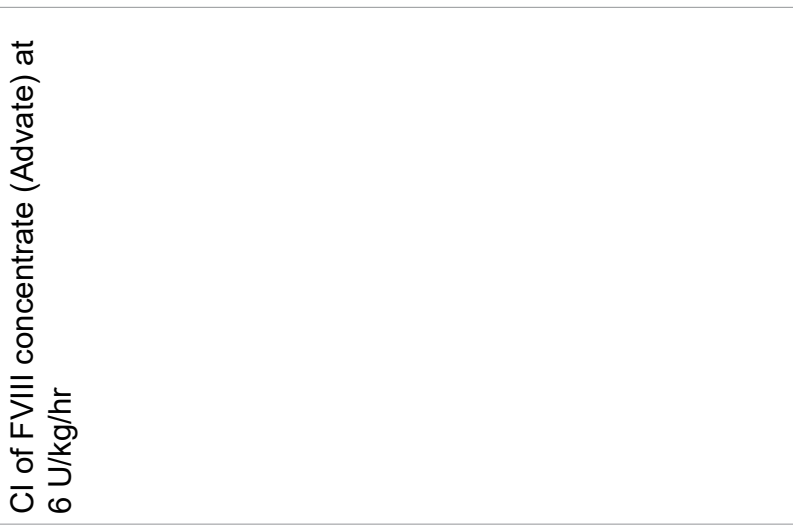 & 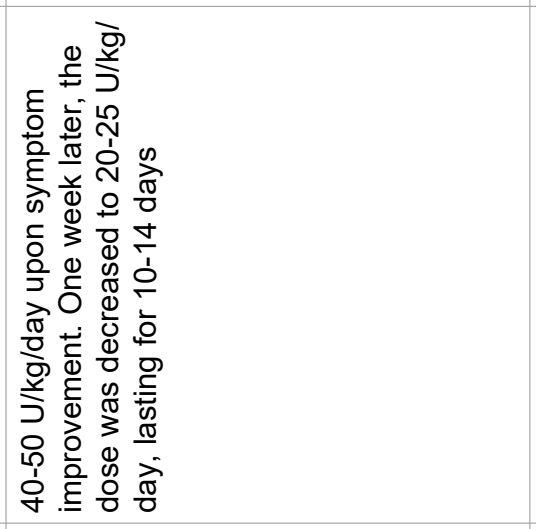 & 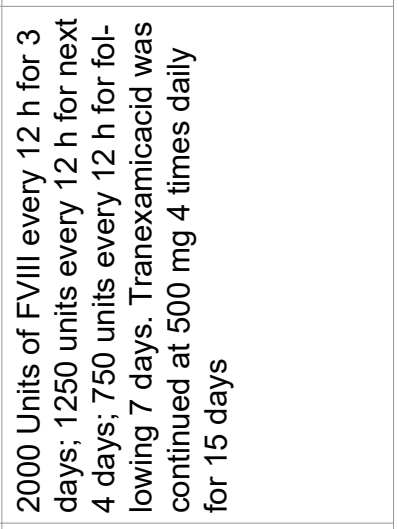 \\
\hline 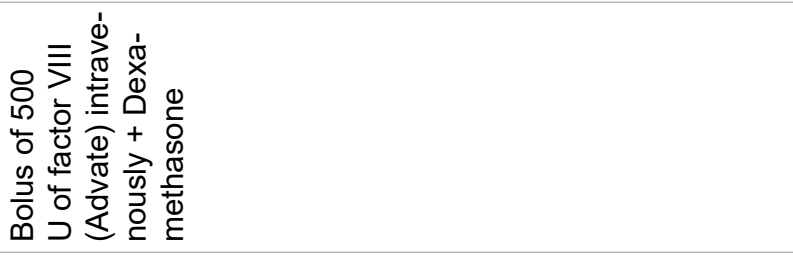 & 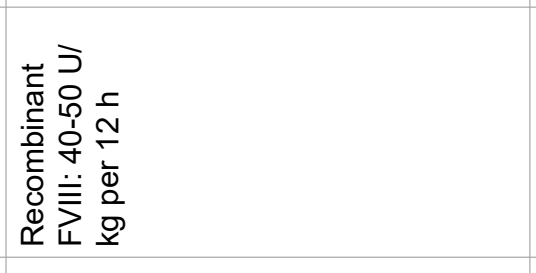 & 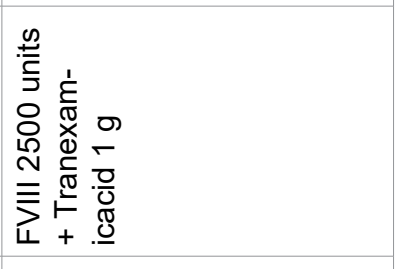 \\
\hline & z & 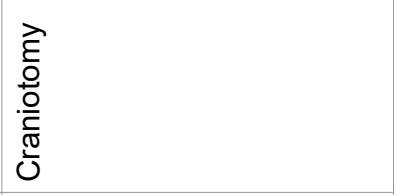 \\
\hline$\stackrel{\circ}{\mathrm{v}}$ & 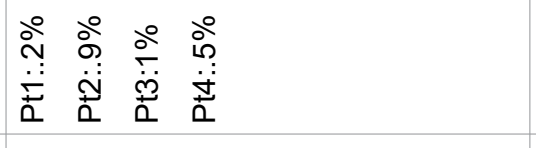 & $\mathrm{Q}$ \\
\hline 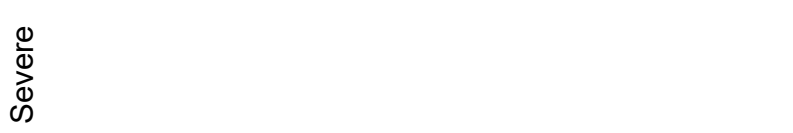 & 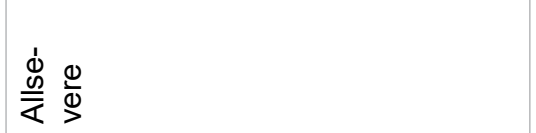 & $\mathrm{Q}$ \\
\hline 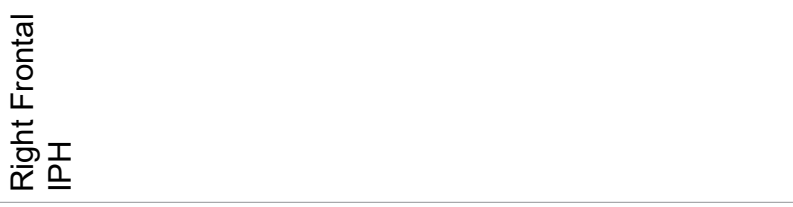 & 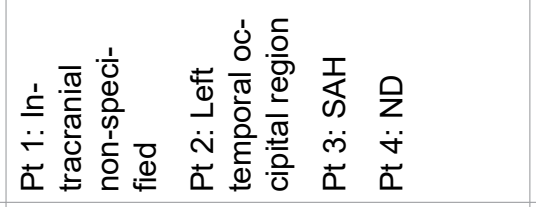 & 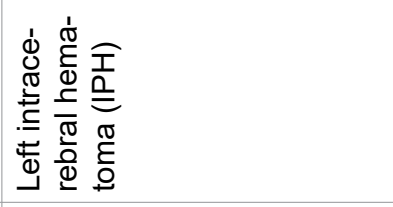 \\
\hline 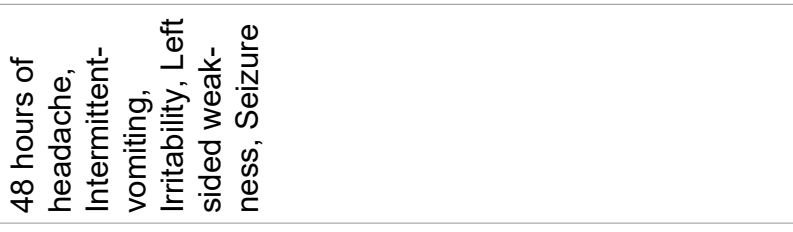 & 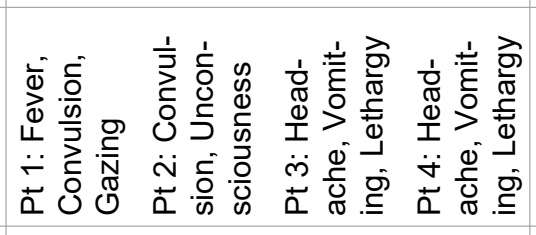 & 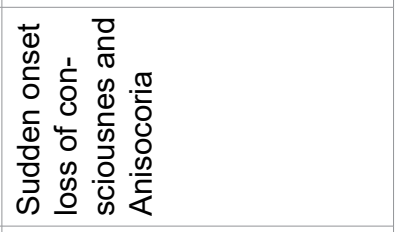 \\
\hline $\begin{array}{l}\stackrel{\circ}{E} \\
\stackrel{+}{\leftarrow}\end{array}$ & 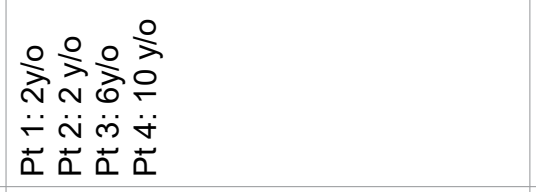 & $\begin{array}{l}\stackrel{0}{x} \\
\stackrel{\sigma}{-}\end{array}$ \\
\hline 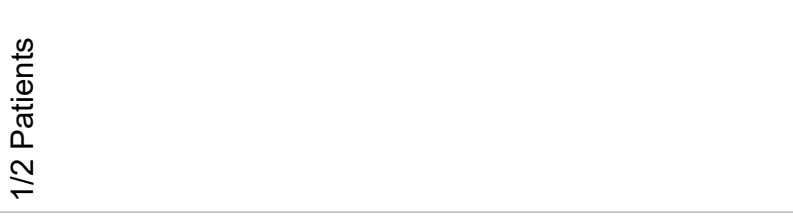 & 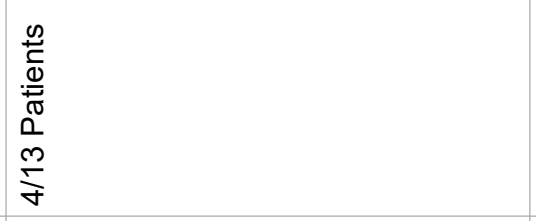 & 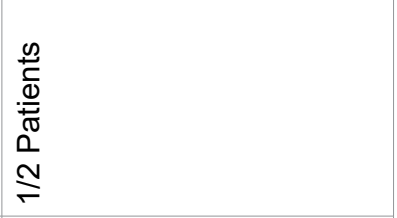 \\
\hline$\stackrel{\infty}{\grave{N}}$ & $\stackrel{\infty}{\stackrel{N}{N}}$ & $\stackrel{\nabla}{\grave{N}}$ \\
\hline 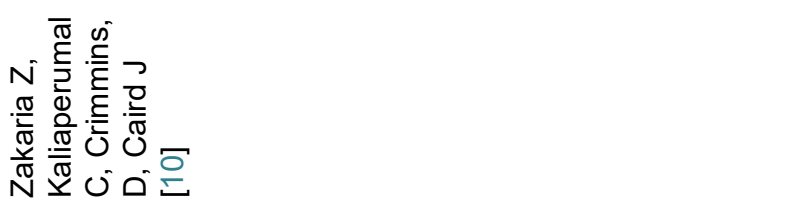 & 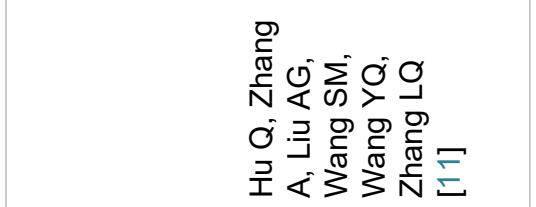 & 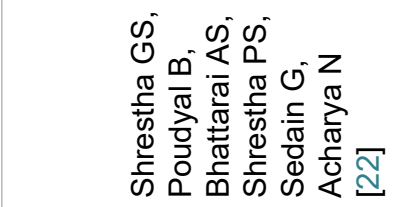 \\
\hline
\end{tabular}




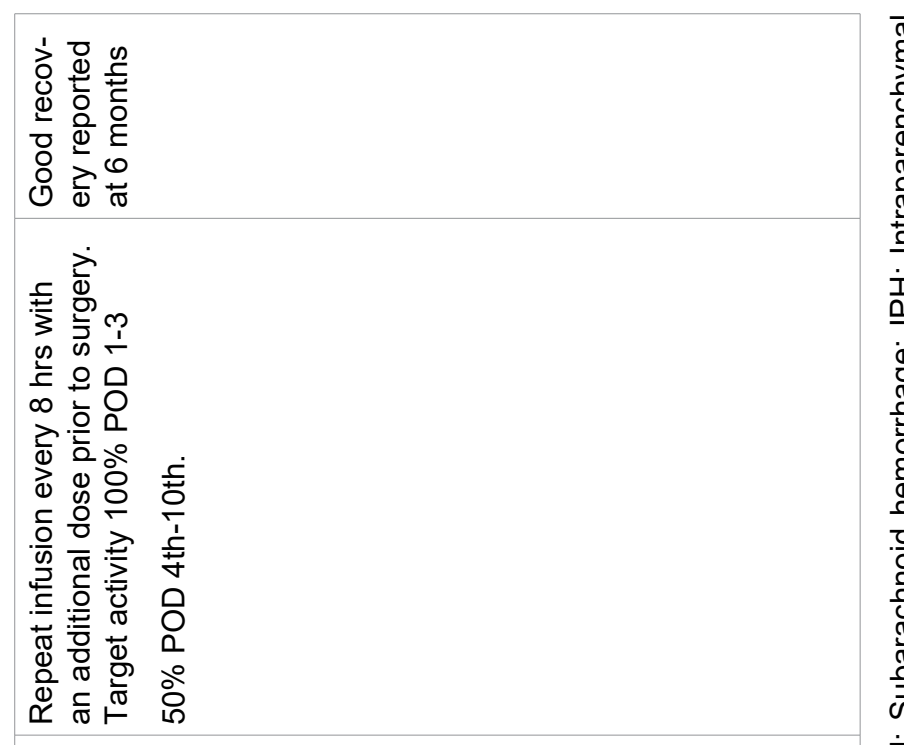

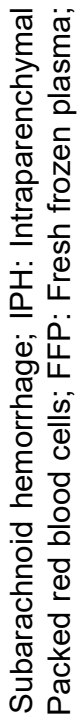

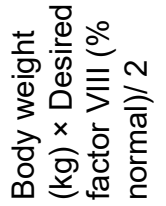

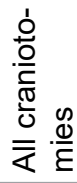

$\stackrel{\circ}{\circ}$

$\bar{\varepsilon}$

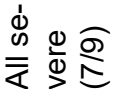

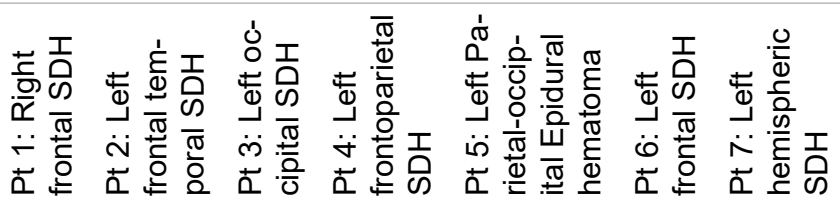

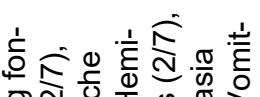

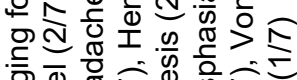

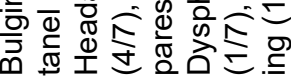

윽옥응 $m$

구는 운

$\ddot{\sim} \ddot{\sim} \ddot{\sim} \ddot{\forall} \ddot{0} \ddot{0}$

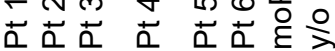

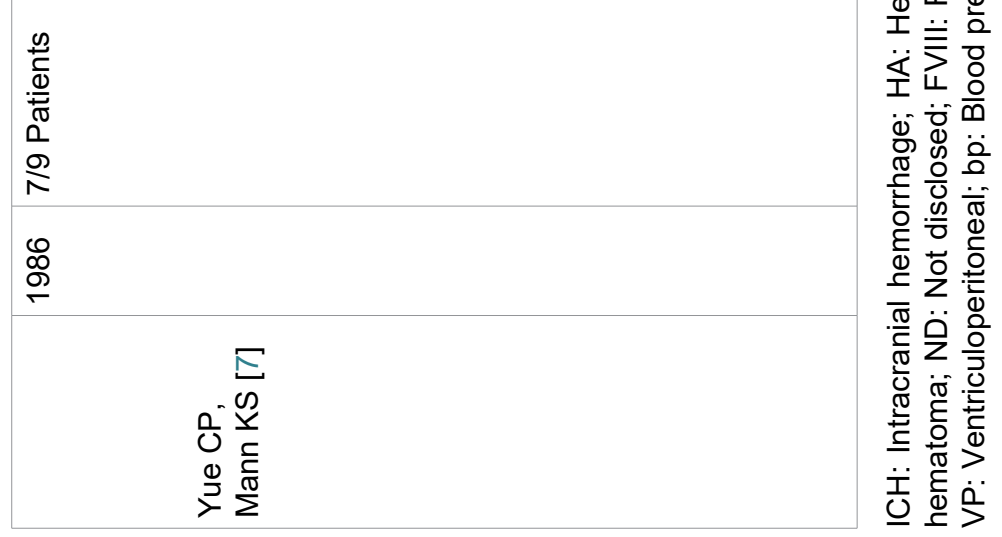


recombinant factor VIII, the $\mathrm{Cl}$ failed to be effective early in the treatment course, and his appropriate response to a regimented bolus schedule.

\section{Conclusion}

Spontaneous intracranial hemorrhage is a morbid and potentially fatal sequela of Hemophilia $A$ and requires a heightened level of suspicion in children less than two years of age who present with altered sensorium. Immediate correction of clotting factor deficiency is paramount prior to neurological surgery and in the immediate post-operative period. In our experience, inadequate response to a continuous infusion of clotting factor concentrate can be corrected with a regimented bolus schedule titrated to $80-100 \%$ factor VIII activity levels; additionally, $50 \mathrm{IU} / \mathrm{kg}$ given prior to additional invasive procedures was effective in achieving adequate hemostasis intra-operatively.

\section{Acknowledgement}

None.

\section{Statement of Ethics}

Ethical approval was not required for this study in accordance with national guidelines.

Written informed consent was obtained from the parent for publication of this case and associated images.

\section{Conflict of Interest Statement}

The authors have no conflicts of interest to declare.

\section{Data Availability Statement}

All data generated during this study are included in this article. Some data cannot be shared for patient confidentiality reasons. Further enquiries can be directed to the corresponding author.

\section{Author Contributions}

Omar Akel \& Blake Taylor: Conception, design, data acquisition, drafting \& editing of the manuscript, critical revision of the article, final approval of the version to be published.

Omar Ashraf, Fareed Jumah \& Bharath Raju: Editing of the manuscript, critical revision of the article, final approval of the version to be published.

Priyank Khandelwal, Margaret Pain, Stephen Johnson, Anil Nanda \& Sudipta Roychowdhury: Critical revision of the article, final approval of the version to be published.

Gaurav Gupta: Conception, design, drafting \& editing of the manuscript, critical revision of the article, final approval of the version to be published.

\section{Funding Sources}

We have not received any financial support from any source.

\section{References}

1. Chalmers EA, Alamelu J, Collins PW, Mathias M, Payne $J$, et al. (2018) Intracranial haemorrhage in children with inherited bleeding disorders in the UK 2003-2015: A national cohort study. Haemophilia 24: 641-647.

2. Srivastava A, Santagostino E, Dougall A, Kitchen S, Sutherland M, et al. (2020) WFH guidelines for the management of hemophilia, 3rd edition. Haemophilia 6: $1-158$.

3. Ljung RC (2008) Intracranial haemorrhage in haemophilia $\mathrm{A}$ and $\mathrm{B}$. Br J Haematol 140: 378-384.

4. Zanon E, Pasca S (2019) Intracranial haemorrhage in children and adults with haemophilia A and B: A literature review of the last 20 years. Blood Transfus 17: 378-384.

5. Iorio A, Stonebraker JS, Chambost H, Makris M, Coffin D, et al. (2019) Establishing the prevalence and prevalence at birth of hemophilia in males: A meta-analytic approach using national registries. Ann Intern Med 171: 540-546.

6. Antunes SV, Vicari P, Cavalheiro S, Bordin JO (2003) Intracranial haemorrhage among a population of haemophilic patients in Brazil. Haemophilia 9: 573-577.

7. Yue CP, Mann KS (1986) The surgical management of intracranial hematomas in hemophiliac children - A prospective study. Child's Nerv Syst 2: 5-9.

8. Simpson ML, Thompson AA (2011) Recognition and management of hemophilia emergencies. Clin Pediatr Emerg Med 12: 224-232.

9. Nagel K, Pai MK, Paes BA, Chan AK (2013) Diagnosis and treatment of intracranial hemorrhage in children with hemophilia. Blood Coagul Fibrinolysis 24: 23-27.

10. Zakaria Z, Kaliaperumal C, Crimmins D, Caird J (2018) Neurosurgical management in children with bleeding diathesis: Auditing neurological outcome. J Neursurg Pediatr 21: 38-43.

11. Hu Q, Zhang A, Liu AG, Wang SM, Wang YQ, et al. (2018) A retrospective analysis of intracranial hemorrhage in children with hemophilia A. Curr Med Sci 38: 875-879.

12. Bjorkman S, Berntorp E (2001) Pharmacokinetics of coagulation factors: Clinical relevance for patients with haemophilia. Clin Pharmacokinet 40: 815-832.

13. Tiede A, Cid AR, Goldmann G, Jimenez-Yuste V, Pluta $M$, et al. (2020) Body mass index best predicts recovery of recombinant factor viii in underweight to obese patients with severe haemophilia A. Thromb Haemost 120: 277-288.

14. Lee CA, Berntorp EE, Hoots WK, Kaufman AS, Kaufman NL, et al. (2014) Textbook of Hemophilia. John Wiley \& Sons, Hoboken, United Kingdom.

15. Carrea R, Pavlovsky A, Monges J, Tezanos Pinto M, Penchansky $L$ (1968) Medical and surgical management of intracranial bleeding in hemophilic children. Acta Neurol Latinoam 14: 155-173.

16. Seeler RA, Imana RB (1973) Intracranial hemorrhage in patients with hemophilia. J Neurosurg 39: 181.

17. Stancic-Rokotov F, Kogler A, Lupret V (1980) Intracerebral haematoma in an infant with haemophilia A. Acta neurochir 52: 67-71.

18. Balak N, Silav G, Kilic Y, Timur C, Elmaci I (2007) Successful surgical treatment of a hemophiliac infant with nontraumatic acute subdural hematoma. Surg Neurol 68: 537-540.

19. Cermelj M, Negro F, Schijman E, Ferro AM, Acerenza M, et 
al. (2004) Neurosurgical intervention in a haemophilic child with a subdural and intracerebral haematoma. Haemophilia 10: 405-407.

20. Bergin SM, Dunn AL, Smith LGF, Drapeau AI (2019) Management of hydrocephalus in infants with severe hemophilia A: Report of 2 cases. J Neursurg Pediatr 23: 159-163.

21. Bray GL, Luban NLC (1987) Hemophilia presenting with intracranial hemorrhage: An approach to the infant with intracranial bleeding and coagulopathy. Am J Dis Child 141: $1215-1217$.

22. Shrestha GS, Poudyal B, Bhattarai AS, Shrestha PS, Sedain $G$, et al. (2014) Perioperative management of two cases of hemophilia with spontaneous intracerebral hemorrhage undergoing emergency craniotomy in resource constrained setup of Nepal. Indian J Crit Care Med 18: 754-756.

23. Hathaway WE, Christian MJ, Clarke SL, Hasiba U (1984) Comparison of continuous and intermittent Factor VIII concentrate therapy in hemophilia A. Am J Hematol 17: 8588.

24. Gouw SC, van der Bom JG, Marijke van den Berg H (2007) Treatment-related risk factors of inhibitor development in previously untreated patients with hemophilia A: The CANAL cohort study. Blood 109: 4648-4654.

25. Wight J, Paisley S (2003) The epidemiology of inhibitors in haemophilia A: A systematic review. Haemophilia 9: 418435. 